The style of the book is on the whole simple and clear (what does the subject-matter admit of else?), but one is occasionally startled by such English as this (p. 38): "In birds, at about the middle, the mid-gut bears a blind tube," or as this (p. 223): "The lampreys feed upon the mucus and blood which they rasp from fishes."

The method of treatment is then strictly morphological-the first part dealing with the morphology of the organs-the second part adding to this so much of external morphology as is of use in classification. Judged as a morphology the book deserves to be commended. But does this warrant the author in calling it a zoology?

A categorical description of the structures of vertebrates so arranged as to suggest their evolution is but a part of zoology. In the opinion of the reviewer it is the least interesting part, and by many modern workers it is regarded as the least important. It would be hard to imagine a college student calling Professor Kingsley's book either interesting or stimulating, though if used as directed in connection with lectures and laboratory work he will surely find it of value. It is easier to point out faults than to show how they may be remedied, but why, may we ask, should three pages be given to the mouth, lips, teeth and tongue, and no word said of the chain of causal relations connecting lip development in mammals with the power of mastication, heterodont dentition and articulate speech, so admirably worked up by Gegenbaur? Why an account of the peculiarities of structure of the Raiæ and no word as to the relation of these peculiarities to the mode of life? And so the rest of it: if we are to have pure morphology, why not more of the spirit of Gegenbaur and less of that of Haeckel? When the ideal text-book of zoology is written it will surely deal with causes, not merely with results.

\section{JACOB REIGHARD,}

\section{UNIVERSITY OF MICHIGAN.}

Water-Supply Engineering: The Designing, Construction and Maintenance of Water-Supply Systems, both City and Irrigation. By A. Prescott Folwell, Associate Professor of
Municipal Engineering in Lafayette College. First Edition. New York, John Wiley and Sons. 1900. Octavo, 562 pages and 19 plates. Price, $\$ 4.00$.

The Filtration of Public Water-Supplies. By Allen Hazen. Third Edition, Revised and Enlarged. New York, John Wiley and Sons. 1900. Octavo, 321 pages and 22 plates. Price, $\$ 3.00$.

It is a happy feature of American engineering education that many of the text-books used by the student are also manuals constantly consulted by the engineer in making his designs. In such a system of education there is no conflict between theory and practice, but each supplements and improves the other. Theory is indeed merely the systematic formulation of general laws derived from experience, and practice is the application of theory to the economic production of useful results. Both of the above books are well adapted to class use, both exhibit the details of the latest theories and constructions, and both are of high value to the practicing engineer. The first book covers the wide field of all the features of water works, while the second treats of that special part concerned with the improvement of the quality of the water.

Professor Folwell has succeeded well in presenting the principles and practice of this wide field in a single volume. The theoretical discussions may sometimes be criticised as rather incomplete, but it is evidently intended that the reader should have a good knowledge of applied mechanics and hydraulics. The question of the force of impact caused by a moving body or stream of water, which is always puzzling to practical men, especially needs correction and revision on pages 229 and 247 . On the whole, however, the theory seems as well presented as can be done in such limited space. The practical details relate largely to the water supplies of cities and towns, irrigation systems being properly given a subordinate place. The subject of designing which includes quantity and quality of water and the details of the systems of collection, purification, and distribution, covers $45 \%$ pages, while construction and operation are treated in 94 pages. Methods of cleaning water mains, of thawing out frozen 
pipes, and of preventing corrosion from electrolysis are well discussed. Pumping systems are treated more fully than usual; this is a step in the right direction, since about 75 per cent. of the water works of the United States are operated by this method, the gravity systems being largely confined to the large towns on the Atlantic and Pacific States. The growing importance of water-supply engineering may be clearly recognized from the fact that the number of water works in the United State in 1898 was about 1600 , while in 1897 , it was about 3200 . The book is well illustrated, clearly written, and will be a valuable aid to all who are planning or operating public water supplies.

The increasing interest in securing purity of water-supplies is not only evidenced by the circumstance that the book of Mr. Hazen has reached its third edition in less than four years, but also by the construction of sand filter beds at seventeen American towns and cities in the last decade. During the same period more than one hundred others have installed mechanical filtration plants. No fact in sanitary engineering is, indeed, more fully established than that the death rate from typhoid fever is materially lowered by filtration, and the present interest of the public gives hope that the time is not far distant when the cities of the United States may take rank with London, Berlin, Vienna, and Amsterdam in freedom from that disease. $\mathrm{Mr}$. Hazen is a high authority on this subject, and, although an advocate of the system of slow filtration through sand beds, his book treats also of the more rapid system of mechanical filters, which in many cases may be installed at less expense. The present edition gives the results of the recent experiments at Louisville, Pittsburg, and Cincinnati, and also valuable information regarding the filter beds of several European cities. Statistics of both systems of filtration are presented in tabular form. These show that the slow sand system is used by cities having an aggregate population of $21,400,000$, of of which $10,200,000$ are in Great Britain and 260,000 in the United States. The aggregate population using mechanical filters in the United States and Canada is nearly $1,600,000$, while this system is practically unemployed in other countries. At the present time only about onetenth of the cities and towns of the United States have filtered water supplies. The book of Mr. Hazen, as well as the large plant recently built at Albany, N. Y., under his supervision, will have much influence in inducing other cities to inaugurate effective methods for the purification of their water supplies.

\section{Mansfield Merriman.}

California Mines and Minerals. Published by the California Miners' Association, under the direction of Edward H. Benjamin, Secretary for the California Meeting of the American Institute of Mining Engineers. San Francisco, Calif. 1899. Vol. 8. Pp. 450.

This treatise upon the mines and mining of California is dedicated to the members of the American Institute of Mining Engineers 'as a souvenir of their visit to California' in September and October, 1899 ; but it is a vastly more important and valuable work than the usual 'souvenir.' It constitutes a very valuable treatise upon the great industry to which it is devoted and is full of important information, valuable historical facts and industrial statistics. It is a large volume, handsomely printed, extensively and well illustrated, well made and substantially bound. Its market value is stated to be five dollars and the munificence of the Californian is well exhibited in the fact that a copy was supplied to every member of the visiting Society.

The contents consist of thirty-five papers by well-informed writers and often the ablest in their respective departments. In these chapters are described the topography, geology and mineral deposits of the various mining counties of the State, the methods of working, the statistics of production, and the special conditions of exploitation and development of the more interesting fields, especially those in which the precious metals are produced in largest quantity. Regarding the most important products, gold and silver, copper, borax, bituminous and asphaltic rock, quicksilver, and petroleum, the ground is remarkably well covered. We note that the output of silver has less value than that of petroleum and that quicksilver has fifty per cent. larger value than the former. 